\title{
FITOSSANIDADE
}

\section{EFEITO DA INFESTAÇÃO DE ENNEOTHRIPS FLAVENS MOULTON SOBRE O DESENVOLVIMENTO DE CULTIVARES DE AMENDOIM $\left({ }^{1}\right)$}

\author{
ANDRÉ LUIZ LOURENÇÃO $\left({ }^{2 *}, 6\right)$; ANDREA ROCHA ALMEIDA DE MORAES $\left({ }^{3}\right)$; \\ IGNÁCIO JOSÉ DE GODOY ( $\left(^{4}\right)$; GLÁUCIA MARIA BOVI AMBROSANO $\left({ }^{5}\right)$
}

\begin{abstract}
RESUMO
Com o objetivo de avaliar a influência do ataque de Enneothrips flavens Moulton (Thysanoptera: Thripidae), no desenvolvimento de cultivares de amendoim, foi implantado um experimento em campo, no ano agrícola de 2001/2002, nas localidades paulistas de Campinas e Pindorama. Avaliaram-se IAC-Tatu-ST, IAC 5 e IAC 22, cultivares de porte ereto e Runner IAC 886, Tégua e IAC-Caiapó, de porte rasteiro, com e sem controle químico da praga. O delineamento adotado foi o de blocos ao acaso, com parcelas subdivididas, com seis repetições, onde as parcelas corresponderam aos tratamentos com e sem controle químico do tripes, e as subparcelas, às cultivares de amendoim. Para a avaliação da infestação de tripes, foram realizadas amostragens a partir dos 29 dias após o plantio (DAP), quando se coletaram dez folíolos fechados por subparcela. Para a contagem do número de brotos por planta, coletaram-se cinco plantas por parcela a partir dos 29 DAP, até próximo ao final do ciclo das cultivares. Determinouse a matéria seca das plantas somente em Campinas, coletando-se cinco plantas por parcela, aos 29, 56, 85, 99, 112 e $125 \mathrm{DAP}$, com posterior secagem artificial da parte vegetativa e da parte reprodutiva. Foram observadas nas plantas de todas as cultivares, nas parcelas não tratadas, as maiores infestações de E. flavens aos 56-57 DAP, e em Pindorama houve um pico de infestação inicial aos 29 DAP. Em função da cultivar, a falta de controle do tripes acarretou diminuição na emissão de brotos e no desenvolvimento vegetativo das plantas.
\end{abstract}

Palavras-chave: Arachis hypogaea, Thysanoptera, Thripidae, resistência de plantas a insetos

\section{ABSTRACT \\ EFFECT OF ENNEOTHRIPS FLAVENS INFESTATION ON PLANT DEVELOPMENT OF PEANUT CULTIVARS}

A field experiment was carried out during the 2001/2002 growing season, in Campinas and Pindorama, São Paulo State, Brazil, to evaluate the influence of Enneothrips flavens Moulton (Thysanoptera: Thripidae) on development of peanut cultivars. The treatments comprised three cultivars of the upright type (IAC Tatu ST, IAC 5 and IAC 22) and three of the runner type (Runner IAC 886, Tegua and IAC Caiapo), with and without insect control. The experimental design was a split plot in completely ramdomized blocks and six replications. Main plots consisted of control and no control of thrips, and the cultivars were the subplots. For the evaluations of thrips infestation, leaf samplings were made starting at 29 days after planting (DAP). Each sample consisted of ten young leaves per plot, at the stage prior to their opening. For the evaluation of the number of buds per plant, five plants per plot were harvested from 29 DAP to the maturity stage of each cultivar. To determine the dry matter content, five plants per plot were harvested at Campinas at 29, 56, 85, 99, 112 and 125 DAP, following artificial drying. At both locations, the mean number of thrips per leaflet peaked at 56-57 DAP; in Pindorama, an early peak occurred at 29 DAP. Depending on the cultivar, the lack of control of E. flavens reduced the number of buds per plant and the vegetative growth.

Key words: Arachis hypogaea, Thysanoptera, Thripidae, host plant resistance.

$\left({ }^{1}\right)$ Recebido para publicação em 22 de novembro de 2006 e aceito em 21 de junho de 2007.

$\left({ }^{2}\right)$ Centro de Fitossanidade (IAC), Caixa Postal 28, 13001-970, Campinas (SP). E-mail: andre@iac.sp.gov.br $\left(^{*}\right)$ Autor correspondente.

$\left({ }^{3,4}\right)$ Centro de Grãos e Fibras, Instituto Agronômico (IAC), Campinas (SP). E-mail: andreamoraes@gmail.com; ijgodoy@iac.sp.gov.br;

$\left({ }^{5}\right)$ Universidade Estadual de Campinas (UNICAMP-FOP), Caixa Postal 52, 13414-018 Piracicaba (SP). E-mail: glaucia@fop.unicamp.br

$\left({ }^{6}\right)$ Bolsista de produtividade em pesquisa do CNPq, 


\section{INTRODUÇÃO}

No Brasil, são produzidas aproximadamente 267 mil toneladas anuais de amendoim (Arachis hypogaea L.), sendo o Estado de São Paulo o principal Estado produtor, atendendo a demanda brasileira com cerca de 208 mil toneladas em uma área plantada de aproximadamente $80 \mathrm{mil}$ hectares. Outras regiões como o Nordeste, o Sul e o Centro-Oeste, contribuem com $20 \%$ a $30 \%$ da produção nacional (CONAB, 2006).

A cultura do amendoim normalmente é afetada por várias pragas e doenças, e, com freqüência, os prejuízos são consideráveis se os controles fitossanitários não forem aplicados, ou então, realizados precariamente (LASCA et al., 1983; MORAES e Godoy, 1997). Em termos de danos econômicos, a principal praga do amendoim no Brasil é o tripes Enneothrips flavens Moulton (Monteiro et al., 1999; GALLO et al., 2002). É de grande importância o conhecimento dos efeitos de infestação dessa praga sobre diferentes cultivares de amendoim, visando encontrar genótipos mais resistentes ao seu ataque, pois, segundo Moraes et al. (2005), a ausência do controle de E. flavens provoca reduções de produção entre 19,5 e 62,7\%, dependendo do nível de infestação, da cultivar utilizada e do local de plantio. Em experimento de campo realizado em Jaboticabal (SP), BOIÇA JUNIOR et al. (2004) verificaram diferenças na infestação desses tripes em nove cultivares de amendoim, o que levou esses autores a sugerir a ocorrência de fatores de resistência nos genótipos menos atacados. Este trabalho teve por objetivo estudar a incidência natural de tripes durante o ciclo de seis cultivares representativas das duas subespécies de amendoim cultivado, comparando o desenvolvimento das plantas com e sem controle da praga, em condições de campo, em duas localidades do Estado de São Paulo.

\section{MATERIAL E MÉTODOS}

O trabalho constou de um experimento, desenvolvido em campo em duas localidades do Estado de São Paulo: em Campinas, no Centro Experimental do Instituto Agronômico (IAC), e em Pindorama, no Pólo Regional de Desenvolvimento Centro-Norte, Unidade Experimental de Pindorama.

O experimento foi instalado em Campinas, em 10/12/2001 e em Pindorama, em 11/12/2001, em esquema de parcelas subdivididas, com delineamento em blocos ao acaso, com seis repetições. As parcelas corresponderam aos tratamentos, com e sem controle químico do tripes (parcelas tratadas e parcelas não tratadas) e, as subparcelas, às seis cultivares de amendoim, sendo três delas de hábito de crescimento ereto e ciclo curto, e três de hábito de crescimento rasteiro e ciclo longo (Tabela 1). Cada subparcela constou de quatro linhas de 10 metros de comprimento de cada cultivar, sendo semeadas 150 sementes por linha. $\mathrm{O}$ espaçamento entre linhas foi o recomendado de acordo com o tipo vegetativo da cultivar, ou seja, de $90 \mathrm{~cm}$ para as cultivares rasteiras e de $60 \mathrm{~cm}$ para as de porte ereto. Realizou-se desbaste após a emergência das plantas, deixando-se de nove a dez plantas por metro nas cultivares rasteiras, e de 12 a 13 plantas por metro nas cultivares de porte ereto. As doenças foliares foram controladas em todas as parcelas mediante pulverizações com fungicida sistêmico à base de difenoconazole $\left(\right.$ Score $\left.^{\circledR}\right)$, na dosagem de $0,35 \mathrm{~L} \mathrm{ha}^{-1}$ ou $87,5 \mathrm{~g} \mathrm{ha}^{-1}$ de i.a.

Nas parcelas com controle da praga, as sementes foram tratadas antes do plantio com o inseticida thiamethoxam (Cruiser $700 \mathrm{WS}^{\circledR}$ ), na dose de $100 \mathrm{~g}$ do produto/ $100 \mathrm{~kg}$ de sementes, ou $70 \mathrm{~g}$ de i.a./100 kg de semente que, de acordo com SCARPELLINI e Nakamura (2002), controla E. flavens, podendo proporcionar produção de amendoim em casca superior a $5.300 \mathrm{~kg} \mathrm{ha}^{-1}$. A partir dos 40 dias após o plantio (DAP), as parcelas foram pulverizadas com thiamethoxam, na formulação de granulado dispersível (Actara $250 \mathrm{WG}^{\circledR}$ ), sendo estas pulverizações repetidas a intervalos de 10 a 19 dias em Campinas e de 14 dias em Pindorama, até os 30 dias da colheita, e na dosagem de $100 \mathrm{~g} \mathrm{ha}^{-1}$, ou $25 \mathrm{~g}$ $\mathrm{ha}^{-1}$ de i.a., ou ainda, $7 \mathrm{mg}$ do produto na bomba motorizada de capacidade de 15 litros.

\subsection{Instalação e manejo do experimento em Campinas}

O terreno de plantio do experimento foi previamente calcariado na base de $2 \mathrm{t} \mathrm{ha}^{-1}$, com saturação por bases de $60 \%$. Antes do plantio, foi feita uma adubação de N-P-K na dosagem de $125 \mathrm{~kg}$ da fórmula 8-28-16 por hectare, ou seja, $115 \mathrm{~g}$ da fórmula por linha de plantio, segundo RAIJ et al. (1997). As aplicações foliares de thiamethoxam foram realizadas em $17 / 1 ; 31 / 1 ; 19 / 2 ; 4 / 3 ; 14 / 3$ e $27 / 3 / 2002$, ou seja, aos $38,52,71,84,94$, e 107 DAP. As pulverizações com difenoconazole iniciaram-se aos $50 \mathrm{DAP}$, prosseguiram até próximo ao final do ciclo de cada cultivar e ocorreram nas seguintes datas: $29 / 1 ; 15 / 2 ; 28 / 2 ; 18 /$ 3 e $27 / 3 / 2002$, ou seja, aos 50, 67, 80, 98 e 107 DAP.

\subsection{Instalação e manejo do experimento em Pindorama}

Foi aplicado calcário durante o preparo da área experimental, na dosagem de $2 \mathrm{t} \mathrm{ha}^{-1}$. Antes do plantio, realizou-se adubação de N-P-K na dosagem 
de $125 \mathrm{~kg}$ da fórmula 8-28-16 por hectare (RAIJ et al., 1997). As aplicações foliares de thiamethoxam nas parcelas tratadas foram feitas em $22 / 1 ; 5 / 2 ; 19 / 2 ; 5 /$ 3 e 19/3/2002, portanto aos 42, 56, 70, 84, 98 DAP.
As pulverizações com difenoconazole iniciaram-se aos 50 DAP e prosseguiram até próximo ao fim do ciclo de cada cultivar, em $24 / 1 ; 7 / 2 ; 21 / 2 ; 7 / 3$ e $21 /$ $3 / 2002$, ou seja, aos 44,58, 72, 86 e 100 DAP.

Tabela 1. Infestação (número de tripes/folíolo) de Enneothrips flavens, em oito épocas de avaliação durante o ciclo das plantas, em seis cultivares de amendoim, sob infestação natural em campo. Campinas (SP), 2001/2002

\begin{tabular}{|c|c|c|c|c|c|c|c|c|c|c|}
\hline \multirow{2}{*}{$\begin{array}{l}\text { Tratamento } \\
\text { inseticida }\end{array}$} & \multirow{2}{*}{ Cultivar } & \multirow{2}{*}{ Porte } & \multicolumn{8}{|c|}{ Dias após o plantio } \\
\hline & & & 29 & 42 & 56 & 71 & 85 & 99 & 112 & 125 \\
\hline \multirow[t]{6}{*}{ Tratado } & IAC-Tatu-ST & Ereto & $0,03 \mathrm{a}$ & $0,03 \mathrm{a}$ & $0,03 \mathrm{a}$ & $0,10 \mathrm{a}$ & $0,07 \mathrm{a}$ & $0,05 \mathrm{a}$ & - & - \\
\hline & IAC 5 & & $0,10 \mathrm{a}$ & $0,02 \mathrm{a}$ & $0,03 \mathrm{a}$ & $0,28 \mathrm{a}$ & $0,05 \mathrm{a}$ & $0,05 \mathrm{a}$ & - & - \\
\hline & IAC 22 & & $0,03 \mathrm{a}$ & $0,05 \mathrm{a}$ & $0,07 \mathrm{a}$ & $0,15 \mathrm{a}$ & $0,05 \mathrm{a}$ & $0,00 \mathrm{a}$ & - & - \\
\hline & Runner IAC 886 & Rasteiro & $0,12 \mathrm{a}$ & $0,00 \mathrm{a}$ & $0,03 \mathrm{a}$ & $0,18 \mathrm{a}$ & $0,07 \mathrm{a}$ & $0,00 \mathrm{a}$ & $0,12 \mathrm{a}$ & - \\
\hline & Tégua & & 0,10 a & $0,00 \mathrm{a}$ & 0,05 a & $0,00 \mathrm{a}$ & $0,12 \mathrm{a}$ & $0,00 \mathrm{a}$ & 0,08 a & - \\
\hline & IAC-Caiapó & & $0,22 \mathrm{a}$ & $0,02 \mathrm{ab}$ & $0,05 \mathrm{ab}$ & $0,07 \mathrm{ab}$ & $0,02 \mathrm{ab}$ & $0,05 \mathrm{ab}$ & $0,00 \mathrm{~b}$ & $0,20 \mathrm{ab}$ \\
\hline Não & IAC-Tatu-ST & Ereto & $0,27 \mathrm{c}$ & $2,42 a b$ & $4,82 \mathrm{a}$ & $1,63 \mathrm{abc}$ & $2,50 \mathrm{ab}$ & $0,92 \mathrm{bc}$ & - & - \\
\hline \multirow[t]{5}{*}{ tratado } & IAC 5 & & $0,73 \mathrm{~b}$ & $2,95 \mathrm{ab}$ & $7,22 \mathrm{a}$ & $2,32 \mathrm{ab}$ & $3,02 \mathrm{ab}$ & $1,48 \mathrm{~b}$ & - & - \\
\hline & IAC 22 & & $0,35 \mathrm{~b}$ & $2,32 a b$ & $5,22 \mathrm{a}$ & 3,03 a & $2,28 \mathrm{ab}$ & $2,05 \mathrm{ab}$ & - & - \\
\hline & Runner IAC 886 & Rasteiro & $0,57 \mathrm{~b}$ & $1,08 \mathrm{~b}$ & $5,32 \mathrm{a}$ & $3,45 \mathrm{ab}$ & $2,45 \mathrm{ab}$ & $1,78 \mathrm{ab}$ & $0,52 \mathrm{~b}$ & - \\
\hline & Tégua & & $0,43 c$ & $1,63 \mathrm{abc}$ & $5,25 \mathrm{a}$ & $4,22 \mathrm{ab}$ & $2,52 \mathrm{abc}$ & $1,73 \mathrm{abc}$ & $0,93 \mathrm{abc}$ & - \\
\hline & IAC-Caiapó & & $0,63 \mathrm{c}$ & $1,27 b c$ & $4,85 \mathrm{a}$ & $3,02 \mathrm{abc}$ & $2,55 \mathrm{ab}$ & $1,30 \mathrm{abc}$ & 0,90 bc 1 & $1,30 \mathrm{abc}$ \\
\hline
\end{tabular}

Médias comparadas entre épocas de avaliação seguidas de mesma letra nas linhas, dentro de cada cultivar, não diferem entre si ao nível de significância pelo teste não-paramétrico de Friedman e comparações múltiplas $(\mathrm{P}<0,05)$.

\subsection{Avaliação da população de E. flavens}

Em ambas as localidades, as contagens de tripes iniciaram-se aos 29 DAP. Foram feitas seis contagens nas cultivares precoces e sete a oito nas de ciclo longo (Tabelas 1 e 2). Em cada avaliação, foram coletados dez brotos apicais por subparcela. Essas amostras foram colocadas em sacos plásticos semipermeáveis e levadas para câmara fria, para preservação durante o processo de contagem. De cada broto de amendoim, retirou-se apenas um folíolo fechado, o mais desenvolvido dos quatro. O folíolo foi colocado sob estereoscópio, aberto com o auxílio de pinça, e contados os números totais de tripes, computando-se o número de ninfas, de adultos vivos e de adultos mortos.

\subsection{Contagem do número de brotos apicais e determinação da matéria seca das plantas}

Os primeiros $5 \mathrm{~m}$ de cada parcela foram reservados apenas para coleta de cinco plantas visualmente representativas da média de desenvolvimento das plantas na parcela. As cinco plantas coletadas tiveram seus números de brotos apicais contados um por um, de modo que os brotos estivessem em estádio semelhante ao dos coletados para a contagem de insetos. Esse procedimento foi realizado aos 29,56, 85, 99, 112 e 125 DAP em Campinas e aos 29, 57 e 85 DAP em Pindorama.

Em seguida, apenas em Campinas, foram coletadas cinco plantas de cada genótipo, separadas em parte aérea (vegetativa) e parte radicular (vagens), reunidas novamente em uma única amostra para serem colocadas em secadora FANEM, com ar quente forçado, por 24 horas a $65-70{ }^{\circ} \mathrm{C}$, para posterior determinação da matéria seca.

Os dados referentes ao número de E. flavens por folíolo, número de brotos por planta e à matéria seca das plantas foram submetidos à análise exploratória pelo programa SAS para determinação da ocorrência ou não de distribuição normal.

Em função dessa análise, foram realizadas análises não-paramétricas pelo teste de Friedman e de comparações múltiplas (Wilcoxon) $(\mathrm{P}<0,05)$, utilizando-se o programa estatístico BioEstat 3.0 (AYres et al., 2003). 


\section{RESULTADOS E DISCUSSÃO}

\subsection{Densidade populacional de E. flavens}

Nas parcelas tratadas, durante todo o ciclo das plantas, a média de tripes por folíolo ficou abaixo de 0,5 para todas as cultivares estudadas, não diferindo entre as épocas, em ambas as localidades, com exceção da cultivar IAC-Caiapó em Campinas, em que se observou, aos 29 DAP, uma média de tripes por folíolo superior à de 112 DAP, quando nenhum inseto foi registrado (Tabelas 1 e 2). Dessa forma, as aplicações de thiamethoxam foram eficientes para o controle geral da praga, cujo nível de ação é de um tripes por folíolo (NAKANO et al., 1981), permitindo a comparação entre os tratamentos com e sem controle do inseto, no experimento das duas localidades. Ainda em Campinas, nas parcelas não tratadas, todas as cultivares tiveram comportamento semelhante, quanto à época de maior infestação, com maior número de tripes por folíolo na terceira avaliação, realizada aos 56 DAP, e com tendência de queda, a partir de então, na quantidade de tripes por folíolo até o final do ciclo das plantas, como observado também por Gabriel et al. (1996).
Em Pindorama (Tabela 2), em todas as cultivares ocorreu um primeiro pico de infestação aos $29 \mathrm{DAP}$, um segundo aos $57 \mathrm{DAP}$, havendo a seguir, da mesma forma que em Campinas, diminuição do número de tripes até a maturação das plantas.

Em Campinas (Tabela 3), quando se comparam as médias das cultivares dentro de cada época, não se detectam diferenças entre elas, embora nas parcelas não tratadas, seja observada tendência de maiores valores para aquelas do grupo ereto, aos 42 DAP. Em 'IAC 5', observou-se a maior média de tripes por folíolo do experimento nas duas localidades, aos 56 DAP.

Já em Pindorama (Tabela 4), comparandose as médias obtidas para as cultivares dentro de cada época, detectaram-se diferenças entre elas apenas aos 43 DAP nas parcelas não tratadas, onde as cultivares de porte ereto, com maior quantidade de tripes por folíolo, diferiram da cultivar IAC-Caiapó. Em 'IAC 5', a exemplo do experimento de Campinas, observou-se uma das mais altas infestações de tripes por folíolo, nas seis épocas de amostragem, especialmente aos 29 DAP, registrando, em termos absolutos, o maior valor (6,73 tripes) durante o experimento.

Tabela 2. Infestação (número de tripes/folíolo) de Enneothrips flavens em sete épocas de avaliação, durante o ciclo das plantas, em seis cultivares de amendoim, sob infestação natural em campo. Pindorama (SP), 2001/2002

\begin{tabular}{|c|c|c|c|c|c|c|c|c|c|}
\hline \multirow{2}{*}{$\begin{array}{l}\text { Tratamento } \\
\text { inseticida }\end{array}$} & \multirow{2}{*}{ Cultivar } & \multirow{2}{*}{ Porte } & \multicolumn{7}{|c|}{ Dias após o plantio } \\
\hline & & & 29 & 43 & 57 & 74 & 85 & 99 & 112 \\
\hline \multirow[t]{6}{*}{ Tratado } & IAC-Tatu-ST & Ereto & $0,05 \mathrm{a}$ & 0,07 a & 0,05 a & $0,00 \mathrm{a}$ & $0,05 \mathrm{a}$ & $0,00 \mathrm{a}$ & - \\
\hline & IAC 5 & & $0,05 \mathrm{a}$ & 0,10 a & $0,32 \mathrm{a}$ & $0,02 \mathrm{a}$ & $0,33 \mathrm{a}$ & $0,02 \mathrm{a}$ & - \\
\hline & IAC 22 & & $0,12 \mathrm{a}$ & $0,10 \mathrm{a}$ & $0,17 \mathrm{a}$ & $0,02 \mathrm{a}$ & $0,03 \mathrm{a}$ & $0,00 \mathrm{a}$ & - \\
\hline & Runner IAC 886 & Rasteiro & $0,02 \mathrm{a}$ & $0,03 \mathrm{a}$ & $0,10 \mathrm{a}$ & $0,02 \mathrm{a}$ & $0,07 \mathrm{a}$ & $0,00 \mathrm{a}$ & - \\
\hline & Tégua & & $0,03 \mathrm{a}$ & $0,00 \mathrm{a}$ & $0,15 \mathrm{a}$ & $0,02 \mathrm{a}$ & $0,12 \mathrm{a}$ & $0,00 \mathrm{a}$ & - \\
\hline & IAC-Caiapó & & $0,00 \mathrm{a}$ & $0,10 \mathrm{a}$ & $0,20 \mathrm{a}$ & 0,03 a & $0,18 \mathrm{a}$ & $0,03 \mathrm{a}$ & $0,50 \mathrm{a}$ \\
\hline \multirow{6}{*}{$\begin{array}{l}\text { Não } \\
\text { tratado }\end{array}$} & IAC-Tatu-ST & Ereto & $3,47 \mathrm{ab}$ & $2,20 \mathrm{abc}$ & $4,03 \mathrm{a}$ & $3,05 \mathrm{ab}$ & $1,28 \mathrm{bc}$ & $0,27 \mathrm{c}$ & - \\
\hline & IAC 5 & & $6,73 \mathrm{a}$ & $1,92 \mathrm{ab}$ & $5,92 \mathrm{a}$ & $3,45 \mathrm{ab}$ & $3,42 \mathrm{ab}$ & $0,58 \mathrm{~b}$ & - \\
\hline & IAC 22 & & $4,10 \mathrm{ab}$ & $2,23 \mathrm{ab}$ & $5,73 \mathrm{a}$ & $2,95 \mathrm{ab}$ & $2,23 \mathrm{ab}$ & $1,08 \mathrm{~b}$ & - \\
\hline & Runner IAC 886 & Rasteiro & $5,35 \mathrm{a}$ & $1,52 \mathrm{ab}$ & $6,18 \mathrm{a}$ & $1,80 \mathrm{ab}$ & $1,57 \mathrm{ab}$ & $0,32 \mathrm{~b}$ & - \\
\hline & Tégua & & $4,12 \mathrm{a}$ & $1,55 \mathrm{ab}$ & $5,08 \mathrm{a}$ & $2,55 \mathrm{ab}$ & $2,37 \mathrm{ab}$ & $0,77 \mathrm{~b}$ & - \\
\hline & IAC-Caiapó & & $5,32 \mathrm{a}$ & $0,53 \mathrm{~b}$ & 3,05 a & $1,38 \mathrm{ab}$ & $1,95 \mathrm{ab}$ & $1,10 \mathrm{ab}$ & $1,63 \mathrm{ab}$ \\
\hline
\end{tabular}

Médias comparadas entre épocas de avaliação seguidas de mesma letra nas linhas, dentro de cada cultivar, não diferem entre si ao nível de significância pelo teste não-paramétrico de Friedman e comparações múltiplas $(\mathrm{P}<0,05)$. 
Tabela 3. Número médio de Enneothrips flavens por folíolo em seis cultivares de amendoim, nas parcelas tratadas e não tratadas com inseticida, em oito épocas durante o ciclo das plantas, sob infestação natural em campo. Campinas (SP), 2001/2002

\begin{tabular}{|c|c|c|c|c|}
\hline \multirow{2}{*}{ Dias após o plantio } & \multirow{2}{*}{ Cultivar } & \multirow{2}{*}{ Porte } & \multicolumn{2}{|c|}{ Número de tripes/ folíolo } \\
\hline & & & tratado & não tratado \\
\hline \multirow[t]{6}{*}{29} & IAC-Tatu-ST & Ereto & 0,03 a $\mathrm{B}$ & 0,27 a $A$ \\
\hline & IAC 5 & & 0,10 a $\mathrm{B}$ & 0,73 a $\mathrm{A}$ \\
\hline & IAC 22 & & 0,03 a B & 0,35 a $\mathrm{A}$ \\
\hline & Runner IAC 886 & Rasteiro & 0,12 a $\mathrm{B}$ & 0,57 a $\mathrm{A}$ \\
\hline & Tégua & & 0,10 a $B$ & 0,43 a $\mathrm{A}$ \\
\hline & IAC-Caiapó & & 0,22 a $\mathrm{B}$ & 0,63 a $A$ \\
\hline \multirow[t]{6}{*}{42} & IAC-Tatu-ST & Ereto & 0,03 a B & 2,42 a $A$ \\
\hline & IAC 5 & & 0,02 a B & 2,95 a $\mathrm{A}$ \\
\hline & IAC 22 & & 0,05 a B & 2,32 a $A$ \\
\hline & Runner IAC 886 & Rasteiro & 0,00 a B & 1,08 a $\mathrm{A}$ \\
\hline & Tégua & & 0,00 a $\mathrm{B}$ & 1,63 a $\mathrm{A}$ \\
\hline & IAC-Caiapó & & 0,02 a B & 1,27 a $\mathrm{A}$ \\
\hline \multirow[t]{6}{*}{56} & IAC-Tatu-ST & Ereto & 0,03 a $\mathrm{B}$ & 4,82 a $\mathrm{A}$ \\
\hline & IAC 5 & & 0,03 a B & 7,22 a $A$ \\
\hline & IAC 22 & & 0,07 a B & 5,22 a $\mathrm{A}$ \\
\hline & Runner IAC 886 & Rasteiro & 0,03 a $B$ & 5,32 a $A$ \\
\hline & Tégua & & 0,05 a B & 5,25 a $A$ \\
\hline & IAC-Caiapó & & 0,05 a B & 4,85 a $\mathrm{A}$ \\
\hline \multirow[t]{6}{*}{71} & IAC-Tatu-ST & Ereto & $0,10 \mathrm{a} B$ & 1,63 a $\mathrm{A}$ \\
\hline & IAC 5 & & 0,28 a $B$ & 2,32 a $A$ \\
\hline & IAC 22 & & 0,15 a B & 3,03 a $A$ \\
\hline & Runner IAC 886 & Rasteiro & 0,18 a B & 3,45 a $A$ \\
\hline & Tégua & & 0,00 a $B$ & 4,22 a $\mathrm{A}$ \\
\hline & IAC-Caiapó & & 0,07 a B & 3,02 a $A$ \\
\hline \multirow[t]{6}{*}{85} & IAC-Tatu-ST & Ereto & 0,07 a B & 2,50 a $A$ \\
\hline & IAC 5 & & 0,05 а B & 3,02 a $A$ \\
\hline & IAC 22 & & 0,05 a B & 2,28 a $A$ \\
\hline & Runner IAC 886 & Rasteiro & 0,07 a B & 2,45 a A \\
\hline & Tégua & & 0,12 a B & 2,52 a $A$ \\
\hline & IAC-Caiapó & & 0,02 a B & 2,55 a $A$ \\
\hline \multirow[t]{6}{*}{99} & IAC-Tatu-ST & Ereto & 0,05 a B & $0,92 \mathrm{a} A$ \\
\hline & IAC 5 & & 0,05 a B & $1,48 \mathrm{a} A$ \\
\hline & IAC 22 & & 0,00 a $B$ & $2,05 \mathrm{a} A$ \\
\hline & Runner IAC 886 & Rasteiro & 0,00 a $B$ & $1,78 \mathrm{a} A$ \\
\hline & Tégua & & 0,00 a B & $1,73 \mathrm{a} A$ \\
\hline & IAC-Caiapó & & 0,05 a B & $1,30 \mathrm{a} \mathrm{A}$ \\
\hline \multirow[t]{3}{*}{112} & Runner IAC 886 & Rasteiro & 0,12 a $\mathrm{B}$ & $0,52 \mathrm{a} \mathrm{A}$ \\
\hline & Tégua & & 0,08 a B & $0,93 \mathrm{a} A$ \\
\hline & IAC-Caiapó & & 0,00 a $\mathrm{B}$ & $0,90 \mathrm{a} A$ \\
\hline 125 & IAC-Caiapó & Rasteiro & $0,20 \mathrm{~B}$ & $1,30 \mathrm{~A}$ \\
\hline
\end{tabular}

Médias seguidas de mesma letras, maiúscula nas linhas (tratamento) e minúscula nas colunas (cultivar), não diferem entre si ao nível de significância pelo teste não-paramétrico de Friedman e comparações múltiplas $(P<0,05)$. 
Tabela 4. Número médio de Enneothrips flavens por folíolo em seis cultivares de amendoim, nas parcelas tratadas e não tratadas com inseticida, em sete épocas durante o ciclo, sob infestação natural em campo. Pindorama (SP), 2001/ 2002

\begin{tabular}{|c|c|c|c|c|}
\hline \multirow{2}{*}{ Dias após o plantio } & \multirow{2}{*}{ Cultivar } & \multirow{2}{*}{ Porte } & \multicolumn{2}{|c|}{ Número de tripes/ folíolo } \\
\hline & & & tratado & não tratado \\
\hline \multirow[t]{6}{*}{29} & IAC-Tatu-ST & Ereto & 0,05 a B & 3,47 a $\mathrm{A}$ \\
\hline & IAC 5 & & 0,05 a B & 6,73 a $A$ \\
\hline & IAC 22 & & 0,12 a B & 4,10 a $\mathrm{A}$ \\
\hline & Runner IAC 886 & Rasteiro & 0,02 a B & 5,35 a $\mathrm{A}$ \\
\hline & Tégua & & $0,03 \mathrm{aBe}$ & 4,12 a $\mathrm{A}$ \\
\hline & IAC-Caiapó & & 0,00 a B & 5,32 a $\mathrm{A}$ \\
\hline \multirow[t]{6}{*}{43} & IAC-Tatu-ST & Ereto & 0,07 a B & 2,20 a A \\
\hline & IAC 5 & & 0,10 a B & 1,92 a $\mathrm{A}$ \\
\hline & IAC 22 & & 0,10 a B & 2,23 a $\mathrm{A}$ \\
\hline & Runner IAC 886 & Rasteiro & 0,03 a B & $1,52 \mathrm{ab} A$ \\
\hline & Tégua & & 0,00 a B & $1,55 \mathrm{ab} A$ \\
\hline & IAC-Caiapó & & 0,10 a B & $0,53 \mathrm{~b} \mathrm{~A}$ \\
\hline \multirow[t]{6}{*}{57} & IAC-Tatu-ST & Ereto & 0,05 a B & 4,03 a $\mathrm{A}$ \\
\hline & IAC 5 & & 0,32 a B & 5,92 a A \\
\hline & IAC 22 & & 0,17 a B & 5,73 a $\mathrm{A}$ \\
\hline & Runner IAC 886 & Rasteiro & 0,10 a B & 6,18 a A \\
\hline & Tégua & & 0,15 a B & 5,08 a A \\
\hline & IAC-Caiapó & & 0,20 a B & 3,05 a $\mathrm{A}$ \\
\hline \multirow[t]{6}{*}{74} & IAC-Tatu-ST & Ereto & 0,00 a B & 3,05 a A \\
\hline & IAC 5 & & 0,02 a B & 3,45 a A \\
\hline & IAC 22 & & 0,02 a B & 2,95 a $\mathrm{A}$ \\
\hline & Runner IAC 886 & Rasteiro & 0,02 a B & 1,80 a $\mathrm{A}$ \\
\hline & Tégua & & 0,02 a B & 2,55 a $\mathrm{A}$ \\
\hline & IAC-Caiapó & & 0,03 a B & 1,38 a $\mathrm{A}$ \\
\hline \multirow[t]{6}{*}{85} & IAC-Tatu-ST & Ereto & 0,05 a B & 1,28 a $\mathrm{A}$ \\
\hline & IAC 5 & & 0,33 a B & 3,42 a A \\
\hline & IAC 22 & & 0,03 а B & 2,23 a A \\
\hline & Runner IAC 886 & Rasteiro & 0,07 a B & 1,57 a $\mathrm{A}$ \\
\hline & Tégua & & 0,12 a B & 2,37 a A \\
\hline & IAC-Caiapó & & 0,18 a B & 1,95 a $\mathrm{A}$ \\
\hline \multirow[t]{6}{*}{99} & IAC-Tatu-ST & Ereto & 0,00 a $\mathrm{A}$ & 0,27 a $\mathrm{A}$ \\
\hline & IAC 5 & & 0,02 a B & 0,58 a A \\
\hline & IAC 22 & & 0,00 a $\mathrm{A}$ & 1,08 a A \\
\hline & Runner IAC 886 & Rasteiro & 0,00 a $\mathrm{A}$ & 0,32 a $\mathrm{A}$ \\
\hline & Tégua & & 0,00 a $\mathrm{A}$ & 0,77 a A \\
\hline & IAC-Caiapó & & 0,03 a B & 1,10 a $\mathrm{A}$ \\
\hline 112 & IAC-Caiapó & Rasteiro & $0,50 \mathrm{~B}$ & $1,63 \mathrm{~A}$ \\
\hline
\end{tabular}

Médias seguidas de mesma letras, maiúscula nas linhas (tratamento) e minúscula nas colunas (cultivar), não diferem entre si ao nível de significância pelo teste não-paramétrico de Friedman e comparações múltiplas $(\mathrm{P}<0,05)$. 


\subsection{Número de brotos apicais}

Tanto em Campinas (Tabela 5) como em Pindorama (Tabela 6), verificam-se os maiores valores de emissão de brotos por planta nas duas primeiras datas, com pico na segunda, avaliadas aos 56 DAP em Campinas e 57 DAP em Pindorama, e declínio de emissão nas épocas seguintes. Destaca-se o desempenho de 'IAC-Caiapó', com novo pico de emissão de brotos aos 112 DAP, em Campinas, nas parcelas não tratadas. Na segunda época de avaliação, em ambas as localidades, nas parcelas tratadas houve tendência para valores maiores, sugerindo que a falta de controle do tripes pode afetar negativamente o crescimento e o desenvolvimento dos brotos apicais, principalmente neste estádio de desenvolvimento das plantas, como já foi relatado por CAMPBELL e WYNNE, citados por Stalker e Campbell (1983).

Tabela 5. Emissão de brotos (número/ planta) em seis épocas de avaliação, durante o ciclo das plantas, em seis cultivares de amendoim, sob infestação natural de Enneothrips flavens em campo. Campinas (SP), 2001/2002

\begin{tabular}{|c|c|c|c|c|c|c|c|c|}
\hline \multirow{2}{*}{$\begin{array}{l}\text { Tratamento } \\
\text { inseticida }\end{array}$} & \multirow{2}{*}{ Cultivar } & \multirow{2}{*}{ Porte } & \multicolumn{6}{|c|}{ Dias após o plantio } \\
\hline & & & 29 & 56 & 85 & 99 & 112 & 125 \\
\hline \multirow[t]{6}{*}{ Tratado } & IAC-Tatu-ST & Ereto & $1,07 \mathrm{ab}$ & $2,50 a$ & $0,60 b$ & $0,17 b$ & - & - \\
\hline & IAC 5 & & $1,73 a b$ & $3,23 a$ & $0,60 b$ & $0,47 b$ & - & - \\
\hline & IAC 22 & & $1,47 a b$ & $2,60 a$ & $0,57 b$ & $0,30 \mathrm{~b}$ & - & - \\
\hline & Runner IAC 886 & Rasteiro & $1,50 \mathrm{ab}$ & $3,47 a$ & $1,03 a b$ & $0,17 b$ & $0,10 \mathrm{~b}$ & - \\
\hline & Tégua & & $1,63 a$ & $2,50 \mathrm{a}$ & $0,63 a$ & $0,47 \mathrm{a}$ & $0,53 a$ & - \\
\hline & IAC-Caiapó & & $1,33 a b$ & $3,17 \mathrm{a}$ & $1,50 \mathrm{ab}$ & $1,33 \mathrm{ab}$ & $1,90 \mathrm{ab}$ & $0,43 b$ \\
\hline Não & IAC-Tatu-ST & Ereto & $0,97 a b$ & $1,97 \mathrm{a}$ & $0,23 b$ & $0,00 \mathrm{~b}$ & - & - \\
\hline \multirow[t]{5}{*}{ tratado } & IAC 5 & & $1,43 a$ & $2,07 \mathrm{a}$ & $0,73 a b$ & $0,10 \mathrm{~b}$ & - & - \\
\hline & IAC 22 & & $1,53 a$ & $2,03 a$ & $0,70 \mathrm{ab}$ & $0,03 b$ & - & - \\
\hline & Runner IAC 886 & Rasteiro & $1,43 a b$ & $2,50 a$ & $0,53 a b$ & $0,03 b$ & $0,07 b$ & - \\
\hline & Tégua & & $1,77 \mathrm{ab}$ & $2,27 a$ & $0,53 a b$ & $0,13 b$ & $0,20 b$ & - \\
\hline & IAC-Caiapó & & $0,97 \mathrm{ab}$ & $2,87 a$ & $1,80 \mathrm{ab}$ & $1,10 \mathrm{ab}$ & $3,73 a$ & $0,33 b$ \\
\hline
\end{tabular}

Médias comparadas entre épocas de avaliação seguidas de mesma letra nas linhas, dentro de cada cultivar, não diferem entre si ao nível de significância pelo teste não-paramétrico de Friedman e comparações múltiplas $(\mathrm{P}<0,05)$.

Tabela 6. Emissão de brotos (número/ planta) em três épocas de avaliação, durante o ciclo das plantas, em seis cultivares de amendoim, sob infestação natural de Enneothrips flavens em campo. Pindorama (SP), 2001/2002

\begin{tabular}{|c|c|c|c|c|c|}
\hline \multirow{2}{*}{$\begin{array}{l}\text { Tratamento } \\
\text { inseticida }\end{array}$} & \multirow{2}{*}{ Cultivar } & \multirow{2}{*}{ Porte } & \multicolumn{3}{|c|}{ Dias após o plantio $^{1}$} \\
\hline & & & 29 & 57 & 85 \\
\hline \multirow[t]{6}{*}{ Tratado } & IAC-Tatu-ST & Ereto & $1,40 \mathrm{ab}$ & $1,68 \mathrm{a}$ & $0,45 \mathrm{~b}$ \\
\hline & IAC 5 & & $1,45 \mathrm{ab}$ & $2,30 \mathrm{a}$ & $0,65 \mathrm{~b}$ \\
\hline & IAC 22 & & $1,38 \mathrm{ab}$ & $1,83 \mathrm{a}$ & $0,35 \mathrm{~b}$ \\
\hline & Runner IAC 886 & Rasteiro & $1,67 \mathrm{ab}$ & $4,10 \mathrm{a}$ & $1,12 \mathrm{~b}$ \\
\hline & Tégua & & $1,60 \mathrm{~b}$ & $4,20 \mathrm{a}$ & $1,85 \mathrm{~b}$ \\
\hline & IAC-Caiapó & & $1,59 \mathrm{~b}$ & $4,97 \mathrm{a}$ & $2,70 \mathrm{ab}$ \\
\hline Não & IAC-Tatu-ST & Ereto & $1,40 \mathrm{ab}$ & $1,63 \mathrm{a}$ & $0,08 \mathrm{~b}$ \\
\hline \multirow[t]{5}{*}{ tratado } & IAC 5 & & $1,42 \mathrm{ab}$ & $2,20 \mathrm{a}$ & $0,27 \mathrm{~b}$ \\
\hline & IAC 22 & & $1,40 \mathrm{a}$ & $1,60 \mathrm{a}$ & $0,37 \mathrm{~b}$ \\
\hline & Runner IAC 886 & Rasteiro & $1,67 \mathrm{ab}$ & $3,68 \mathrm{a}$ & $0,50 \mathrm{~b}$ \\
\hline & Tégua & & $1,73 \mathrm{ab}$ & $3,50 \mathrm{a}$ & $0,70 \mathrm{~b}$ \\
\hline & IAC-Caiapó & & $1,32 \mathrm{ab}$ & $3,92 \mathrm{a}$ & $1,63 \mathrm{~b}$ \\
\hline
\end{tabular}

Médias comparadas entre épocas de avaliação, seguidas de mesma letra nas linhas, dentro de cada cultivar, não diferem entre si ao nível de significância pelo teste não-paramétrico de Friedman e comparações múltiplas $(\mathrm{P}<0,05)$. 
Quanto aos números médios de brotos por planta entre as cultivares dentro de cada época de avaliação, entre cada tratamento, em Campinas (Tabela 7), verificam-se diferenças aos 99 e 112 DAP nas parcelas tratadas; em 'IAC-Caiapó' observou-se maior número de brotos do que 'IAC-Tatu-ST' e 'Runner IAC $886^{\prime}$, aos $99 \mathrm{DAP}$, como também em relação à cultivar Runner IAC 886, aos 112 DAP. Nas parcelas não tratadas, embora as diferenças não tenham sido significativas, observou-se que em 'IAC-Caiapó' houve tendência de emissão de maior número de brotos do que as demais, desde 56 DAP até 112 DAP. Nas comparações entre as parcelas tratadas e não tratadas, em cada cultivar, apenas em 'IAC 5' (aos 56 DAP) e 'Tégua' (aos 99 DAP) notaram-se diferenças, com maior emissão de brotos nas parcelas tratadas.

Tabela 7. Número médio de brotos por planta em seis cultivares de amendoim, nas parcelas tratadas e não tratadas com inseticida, em seis épocas durante o ciclo, sob infestação natural de Enneothrips flavens em campo. Campinas (SP), 2001/2002

\begin{tabular}{|c|c|c|c|c|}
\hline \multirow{2}{*}{ Dias após o plantio } & \multirow{2}{*}{ Cultivar } & \multirow{2}{*}{ Porte } & \multicolumn{2}{|c|}{ Número de brotos/ planta } \\
\hline & & & tratado & não tratado \\
\hline \multirow[t]{6}{*}{29} & IAC-Tatu-ST & Ereto & 1,07 a $\mathrm{A}$ & 0,97 a $\mathrm{A}$ \\
\hline & IAC 5 & & 1,73 a $\mathrm{A}$ & 1,43 a $\mathrm{A}$ \\
\hline & IAC 22 & & 1,47 a A & 1,53 a $\mathrm{A}$ \\
\hline & Runner IAC 886 & Rasteiro & 1,50 a $\mathrm{A}$ & 1,43 a $\mathrm{A}$ \\
\hline & Tégua & & 1,63 a $\mathrm{A}$ & 1,77 a $\mathrm{A}$ \\
\hline & IAC-Caiapó & & 1,33 a $\mathrm{A}$ & 0,97 a $\mathrm{A}$ \\
\hline \multirow[t]{6}{*}{56} & IAC-Tatu-ST & Ereto & 2,50 a $\mathrm{A}$ & 1,97 a $\mathrm{A}$ \\
\hline & IAC 5 & & 3,23 a A & 2,07 a B \\
\hline & IAC 22 & & 2,60 a A & 2,03 a $\mathrm{A}$ \\
\hline & Runner IAC 886 & Rasteiro & 3,47 a A & 2,50 a A \\
\hline & Tégua & & 2,50 a $\mathrm{A}$ & 2,27 a $\mathrm{A}$ \\
\hline & IAC-Caiapó & & 3,17 a $\mathrm{A}$ & 2,87 a $\mathrm{A}$ \\
\hline \multirow[t]{6}{*}{85} & IAC-Tatu-ST & Ereto & 0,60 a A & 0,23 a $\mathrm{A}$ \\
\hline & IAC 5 & & 0,60 a $\mathrm{A}$ & 0,73 a A \\
\hline & IAC 22 & & 0,57 a A & 0,70 a A \\
\hline & Runner IAC 886 & Rasteiro & 1,03 a $\mathrm{A}$ & 0,53 a $\mathrm{A}$ \\
\hline & Tégua & & 0,63 a $\mathrm{A}$ & 0,53 a A \\
\hline & IAC-Caiapó & & 1,50 a $\mathrm{A}$ & 1,80 a A \\
\hline \multirow[t]{6}{*}{99} & IAC-Tatu-ST & Ereto & 0,17 b A & 0,00 a A \\
\hline & IAC 5 & & $0,47 \mathrm{ab} \mathrm{A}$ & 0,10 a A \\
\hline & IAC 22 & & $0,30 \mathrm{ab} A$ & 0,03 a A \\
\hline & Runner IAC 886 & Rasteiro & 0,17 b A & 0,03 a A \\
\hline & Tégua & & $0,47 \mathrm{ab} A$ & 0,13 а B \\
\hline & IAC-Caiapó & & 1,33 a $\mathrm{A}$ & 1,10 a $\mathrm{A}$ \\
\hline \multirow[t]{3}{*}{112} & Runner IAC 886 & Rasteiro & $0,10 \mathrm{bA}$ & 0,07 a A \\
\hline & Tégua & & $0,53 \mathrm{ab} A$ & 0,20 a $\mathrm{A}$ \\
\hline & IAC-Caiapó & & 1,90 a $\mathrm{A}$ & 3,73 a A \\
\hline 125 & IAC-Caiapó & Rasteiro & $0,43 \mathrm{~A}$ & $0,33 \mathrm{~A}$ \\
\hline
\end{tabular}

Médias seguidas de mesmas letras, maiúscula na linha (tratamento) e minúscula na coluna (cultivar), não diferem entre si ao nível de significância pelo teste não-paramétrico de Friedman e comparações múltiplas $(P<0,05)$. 
Em Pindorama (Tabela 8), verificam-se diferenças entre as cultivares, na segunda e na terceira épocas, nas parcelas tratadas. Na segunda, 'IAC-Caiapó' e 'Tégua' tiveram maior número de brotos do que 'IAC-Tatu-ST' e, na terceira, em 'IACCaiapó' e 'Tégua' ocorreu maior número de brotos por planta que 'IAC 22'. Desse modo, considerandose ambas as localidades, pode-se verificar que 'IAC-Caiapó' é a que possui consistentemente maior capacidade para emissão de novos brotos durante a maior parte do ciclo das plantas. Nas parcelas não tratadas, em todas as épocas de amostragem foram detectadas diferenças no número de brotos entre as cultivares. Aos 29 DAP, 'Tégua' mostrou maior número de brotos do que 'IAC-Tatu-ST' e 'IAC 22'. Aos 57 DAP, nas cultivares rasteiras, verificou-se maior quantidade de brotos por planta, diferindo de 'IAC-Tatu-ST' e 'IAC 22'. Aos 85 DAP, observou-se em 'IAC-Caiapó' maior emissão de brotos que em 'IAC-Tatu-ST'. Nas comparações entre as parcelas tratadas e não tratadas, verifica-se que apenas na terceira época houve diferenças, quando 'IAC-TatuST', 'IAC 5' e 'IAC-Caiapó' tiveram menores emissões de brotos nas parcelas não tratadas, indicando que a ausência de controle da praga proporciona redução na quantidade de brotos por planta.

Nas parcelas tratadas, a diferença entre as cultivares quanto ao número de brotos produzidos pode ser atribuída às suas diferentes arquiteturas vegetativas. As cultivares eretas, de ciclo de desenvolvimento vegetativo mais curto do que as rasteiras, têm menor número de ramos, sendo sua arquitetura restrita a uma haste principal e aos ramos primários. As rasteiras possuem ramos de ordem primária, secundária e até terciária (Godoy et al., 1999). Assim, o grau de infestação de tripes em plantas com maior ou menor número de brotos por planta, pode resultar em valores diferentes dos obtidos para número de tripes por folíolo discutido anteriormente (Tabelas 1 e 3, para Campinas e Tabelas 2 e 4, para Pindorama). As cultivares com mesmo número de tripes por folíolo podem ser mais ou menos afetadas por terem mais ou menos "pontos de ataque" para a praga (brotos por planta), conforme dados obtidos por GABRIEL et al. $(1996 ; 1998)$ para as cultivares de ciclo longo IAC-Caiapó e IAC-Jumbo.

Tabela 8. Número de brotos por planta em seis cultivares de amendoim, nas parcelas tratadas e não tratadas com inseticida, em três épocas durante o ciclo, sob infestação natural de Enneothrips flavens em campo. Pindorama (SP), $2001 / 2002$

\begin{tabular}{|c|c|c|c|c|}
\hline \multirow{2}{*}{ Dias após o plantio } & \multirow{2}{*}{ Cultivar } & \multirow{2}{*}{ Porte } & \multicolumn{2}{|c|}{ Número de brotos/ planta } \\
\hline & & & tratado & não tratado \\
\hline \multirow[t]{6}{*}{29} & IAC-Tatu-ST & Ereto & 1,40 a $\mathrm{A}$ & $1,40 \mathrm{~b} \mathrm{~A}$ \\
\hline & IAC 5 & & 1,45 a $\mathrm{A}$ & $1,42 \mathrm{ab} \mathrm{A}$ \\
\hline & IAC 22 & & 1,38 a $\mathrm{A}$ & $1,40 \mathrm{~b} \mathrm{~A}$ \\
\hline & Runner IAC 886 & Rasteiro & 1,67 a $\mathrm{A}$ & $1,67 \mathrm{ab} A$ \\
\hline & Tégua & & 1,60 a $\mathrm{A}$ & $1,73 \mathrm{aA}$ \\
\hline & IAC-Caiapó & & 1,53 a $\mathrm{A}$ & $1,59 \mathrm{ab} \mathrm{A}$ \\
\hline \multirow[t]{6}{*}{57} & IAC-Tatu-ST & Ereto & $1,68 \mathrm{~b} \mathrm{~A}$ & $1,63 \mathrm{~b} \mathrm{~A}$ \\
\hline & IAC 5 & & $2,30 \mathrm{ab} \mathrm{A}$ & $2,20 \mathrm{ab} \mathrm{A}$ \\
\hline & IAC 22 & & $1,83 \mathrm{ab} \mathrm{A}$ & $1,60 \mathrm{~b} \mathrm{~A}$ \\
\hline & Runner IAC 886 & Rasteiro & $4,10 \mathrm{ab} \mathrm{A}$ & 3,68 a $\mathrm{A}$ \\
\hline & Tégua & & 4,20 a $\mathrm{A}$ & 3,50 a $\mathrm{A}$ \\
\hline & IAC-Caiapó & & 4,97 a $\mathrm{A}$ & 3,92 a $\mathrm{A}$ \\
\hline \multirow[t]{6}{*}{85} & IAC-Tatu-ST & Ereto & 0,45 bc $\mathrm{A}$ & $0,08 \mathrm{~b} \mathrm{~B}$ \\
\hline & IAC 5 & & 0,65 abc $\mathrm{A}$ & $0,27 \mathrm{ab} B$ \\
\hline & IAC 22 & & 0,35 с A & $0,37 \mathrm{ab} \mathrm{A}$ \\
\hline & Runner IAC 886 & Rasteiro & 1,12 abc $\mathrm{A}$ & $0,50 \mathrm{abA}$ \\
\hline & Tégua & & $1,85 \mathrm{ab} \mathrm{A}$ & $0,70 \mathrm{ab} A$ \\
\hline & IAC-Caiapó & & 2,70 a $\mathrm{A}$ & 1,63 a $\mathrm{B}$ \\
\hline
\end{tabular}

Médias seguidas de mesmas letras, maiúscula nas linhas (tratamento) e minúscula nas colunas (cultivar), não diferem entre si ao nível de significância pelo teste não-paramétrico de Friedman e comparações múltiplas $(P<0,05)$. 


\subsection{Matéria seca vegetativa}

Comparando-se as quantidades de matéria seca vegetativa acumulada em cada cultivar nas diferentes épocas de amostragens (Tabela 9), observase que, nas parcelas tratadas, 'IAC-Tatu-ST' atingiu seu máximo desenvolvimento vegetativo aos 99 DAP, acumulando $67 \mathrm{~g} /$ planta de matéria seca. Essa cultivar é a mais precoce de todas, atingindo o ponto de colheita entre 100 e 110 dias (IAC, 2000a). Ainda entre as cultivares eretas, 'IAC 5' e 'IAC 22', resultantes de linhagens irmãs do mesmo cruzamento, e que têm ciclo pouco maior que 'IAC-Tatu-ST' (Godor et al., 2001b), também alcançaram a maior massa vegetativa aos 99 DAP.

As cultivares rasteiras Runner IAC 886 e Tégua são vegetativamente muito semelhantes e seu ciclo até a colheita é normalmente de 125 a 130 dias (IAC, 2000b). 'Runner IAC 886' atingiu 81,52 g/planta e 'Tégua' 90,28 g planta $^{-1}$ de matéria seca, aos 112 DAP. Em 'IAC-Caiapó' que, em condições normais, tem ciclo de 130 a 135 dias (Godoy et al., 2001a), aos 112 DAP, observou-se o maior valor de matéria seca vegetativa dentre todas as cultivares: 105,25 g planta $^{-1}$. Aos 125 DAP, ocorreu diminuição da matéria seca vegetativa nessa cultivar, provavelmente devido à estiagem ocorrida na área experimental em momento anterior à época de amostragem, o que ocasionou queda de folhas. Nas parcelas não tratadas, observaram-se curvas semelhantes de matéria seca vegetativa para as cultivares nas seis datas, embora com tendência de menores valores a partir da segunda avaliação.
Quando se compara a matéria seca vegetativa entre as cultivares dentro de cada época de amostragem (Tabela 10), observa-se que, apenas aos 29 DAP, nas parcelas não tratadas, houve diferenças, e na 'IAC 22' ocorreu maior desenvolvimento vegetativo que 'Tégua' e 'IAC-Caiapó'. Confrontandose as cultivares com controle e sem controle de tripes, verifica-se que as parcelas não tratadas foram mais afetadas na parte aérea na segunda época em 'IACTatu-ST', 'IAC 22', 'Runner IAC 886' e 'IAC-Caiapó'; na quarta época em 'IAC-Tatu-ST' e 'Tégua', e, na quinta época, em 'Tégua'. Assim, os efeitos do tripes sobre o desenvolvimento vegetativo ocorreram, com exceção de 'IAC 5', em todas as cultivares, a partir de 56 DAP. Segundo Almeida e Arruda (1962), os danos às plantas ocorrem porque nas folhas, ao se abrirem, observam-se deformações, encarquilhamento e prateamento, com efeitos sobre a capacidade fotossintética da planta. CAstro et al. (1972) e Calcagnolo et al. (1974a; 1974b) também consideraram que os danos causados por tripes em amendoim ocasionaram redução da área foliar.

As diferenças entre os tratamentos com e sem controle foram mais freqüentes aos $56 \mathrm{DAP}$, época coincidente com o pico de infestação do tripes, e nas épocas mais próximas do fim do ciclo das cultivares. 'IAC 5' e 'IAC 22' tiveram as maiores reduções da parte aérea (superiores a $40 \%$ ) quando avaliadas aos 99 DAP, embora não houvesse diferença significativa. 'IAC-Caiapó' foi a menos afetada dos 56 aos 99 DAP, dentre todas as cultivares, mostrando sua capacidade vegetativa de suportar as infestações da praga.

Tabela 9. Peso da matéria seca vegetativa (g) em seis épocas de avaliação, durante o ciclo das plantas, em seis cultivares de amendoim, sob infestação natural de Enneothrips flavens em campo. Campinas (SP), 2001/2002

\begin{tabular}{|c|c|c|c|c|c|c|c|c|}
\hline \multirow{2}{*}{ Tratamento inseticida } & \multirow{2}{*}{ Cultivar } & \multirow{2}{*}{ Porte } & \multicolumn{6}{|c|}{ Dias após o plantio } \\
\hline & & & 29 & 56 & 85 & 99 & 112 & 125 \\
\hline & & & & & $\mathrm{g}$ & 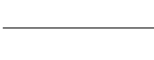 & 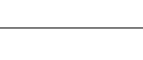 & 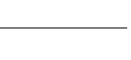 \\
\hline \multirow{6}{*}{ Tratado } & IAC-Tatu-ST & Ereto & $3,62 b$ & $20,67 \mathrm{ab}$ & 61,27 a & $67,00 \mathrm{a}$ & - & - \\
\hline & IAC 5 & & $4,04 \mathrm{~b}$ & $21,14 \mathrm{ab}$ & 58,736 a & $85,25 \mathrm{a}$ & - & - \\
\hline & IAC 22 & & $4,01 \mathrm{~b}$ & $20,75 \mathrm{ab}$ & $58,33 \mathrm{a}$ & $75,25 \mathrm{a}$ & - & - \\
\hline & Runner IAC 886 & Rasteiro & $3,61 \mathrm{~b}$ & $22,39 \mathrm{ab}$ & $77,20 \mathrm{a}$ & $77,05 \mathrm{ab}$ & $81,52 \mathrm{a}$ & - \\
\hline & Tégua & & $3,27 \mathrm{c}$ & $18,73 \mathrm{bc}$ & $70,83 \mathrm{abc}$ & $82,05 \mathrm{ab}$ & $90,28 \mathrm{a}$ & - \\
\hline & IAC-Caiapó & & $3,05 \mathrm{c}$ & $17,86 \mathrm{bc}$ & $75,80 \mathrm{ab}$ & $73,72 \mathrm{abc}$ & 105,25 a & $84,65 \mathrm{ab}$ \\
\hline \multirow{6}{*}{$\begin{array}{l}\text { Não } \\
\text { tratado }\end{array}$} & IAC-Tatu-ST & Ereto & $3,51 \mathrm{~b}$ & $15,89 \mathrm{ab}$ & 46,07 a & $45,55 \mathrm{a}$ & - & - \\
\hline & IAC 5 & & $3,82 \mathrm{~b}$ & $16,72 \mathrm{ab}$ & 48,93 a & $47,25 \mathrm{a}$ & - & - \\
\hline & IAC 22 & & $3,98 \mathrm{~b}$ & $16,19 \mathrm{ab}$ & $45,32 \mathrm{a}$ & $43,23 \mathrm{a}$ & - & - \\
\hline & Runner IAC 886 & Rasteiro & $3,38 \mathrm{~b}$ & $16,34 \mathrm{ab}$ & 76,83 a & $57,57 \mathrm{ab}$ & 71,75 a & - \\
\hline & Tégua & & $2,99 \mathrm{~b}$ & $17,66 \mathrm{ab}$ & 54,60 a & 53,57 a & 60,65 a & - \\
\hline & IAC-Caiapó & & $2,64 \mathrm{~b}$ & $15,21 \mathrm{ab}$ & $61,57 \mathrm{a}$ & $64,67 \mathrm{a}$ & 85,65 a & $60,80 \mathrm{a}$ \\
\hline
\end{tabular}

Médias comparadas entre épocas de avaliação, seguidas de mesma letra nas linhas, dentro de cada cultivar, não diferem entre si ao nível de significância pelo teste não-paramétrico de Friedman e comparações múltiplas $(\mathrm{P}<0,05)$. 
Tabela 10. Peso da matéria seca vegetativa $(\mathrm{g})$ de seis cultivares de amendoim, nas parcelas tratadas e não tratadas com inseticida, em seis épocas durante o ciclo, em condições de infestação natural de Enneothrips flavens em campo. Campinas (SP), 2001/2002

\begin{tabular}{|c|c|c|c|c|}
\hline \multirow{2}{*}{ Dias após o plantio } & \multirow{2}{*}{ Cultivar } & \multirow{2}{*}{ Porte } & \multicolumn{2}{|c|}{ Matéria seca vegetativa } \\
\hline & & & tratado & não tratado \\
\hline & & & 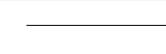 & 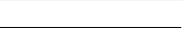 \\
\hline \multirow[t]{6}{*}{29} & IAC-Tatu-ST & Ereto & 3,62 a $A$ & $3,51 \mathrm{ab} \mathrm{A}$ \\
\hline & IAC 5 & & 4,04 a $\mathrm{A}$ & $3,82 \mathrm{ab} A$ \\
\hline & IAC 22 & & 4,01 a $\mathrm{A}$ & 3,98 a $\mathrm{A}$ \\
\hline & Runner IAC 886 & Rasteiro & 3,61 a $A$ & $3,38 \mathrm{ab} \mathrm{A}$ \\
\hline & Tégua & & 3,27 a $\mathrm{A}$ & $2,99 \mathrm{~b} \mathrm{~A}$ \\
\hline & IAC-Caiapó & & 3,05 a $\mathrm{A}$ & $2,64 \mathrm{~b} \mathrm{~A}$ \\
\hline \multirow[t]{6}{*}{56} & IAC-Tatu-ST & Ereto & 20,67 a $\mathrm{A}$ & 15,89 a B \\
\hline & IAC 5 & & 21,14 a $\mathrm{A}$ & 16,72 a $\mathrm{A}$ \\
\hline & IAC 22 & & 20,75 a $\mathrm{A}$ & 16,19 a $B$ \\
\hline & Runner IAC 886 & Rasteiro & 22,39 a $\mathrm{A}$ & 16,34 a B \\
\hline & Tégua & & 18,73 a $\mathrm{A}$ & 17,66 a $\mathrm{A}$ \\
\hline & IAC-Caiapó & & 17,86 a $\mathrm{A}$ & 15,21 a B \\
\hline \multirow[t]{6}{*}{85} & IAC-Tatu-ST & Ereto & 61,27 a $\mathrm{A}$ & 46,07 a $\mathrm{A}$ \\
\hline & IAC 5 & & 58,73 a $\mathrm{A}$ & 48,93 a $\mathrm{A}$ \\
\hline & IAC 22 & & 58,33 a $\mathrm{A}$ & 45,32 a $\mathrm{A}$ \\
\hline & Runner IAC 886 & Rasteiro & 77,20 a $\mathrm{A}$ & 76,83 a $\mathrm{A}$ \\
\hline & Tégua & & 70,83 a $\mathrm{A}$ & 54,60 a $\mathrm{A}$ \\
\hline & IAC-Caiapó & & 75,80 a $\mathrm{A}$ & 61,57 a $\mathrm{A}$ \\
\hline \multirow[t]{6}{*}{99} & IAC-Tatu-ST & Ereto & 67,00 a $\mathrm{A}$ & 45,55 а B \\
\hline & IAC 5 & & 85,25 a $\mathrm{A}$ & 47,25 a $\mathrm{A}$ \\
\hline & IAC 22 & & 75,25 a $\mathrm{A}$ & 43,23 a $\mathrm{A}$ \\
\hline & Runner IAC 886 & Rasteiro & 77,05 a $\mathrm{A}$ & 57,57 a $\mathrm{A}$ \\
\hline & Tégua & & 82,05 a $\mathrm{A}$ & 53,57 a B \\
\hline & IAC-Caiapó & & 73,72 a $\mathrm{A}$ & 64,67 a $A$ \\
\hline \multirow[t]{3}{*}{112} & Runner IAC 886 & Rasteiro & 81,52 a $\mathrm{A}$ & 71,75 a $\mathrm{A}$ \\
\hline & Tégua & & 90,28 a $\mathrm{A}$ & 60,65 a B \\
\hline & IAC-Caiapó & & 105,25 a $\mathrm{A}$ & 85,65 a $A$ \\
\hline 125 & IAC-Caiapó & Rasteiro & $84,65 \mathrm{~A}$ & $60,80 \mathrm{~A}$ \\
\hline
\end{tabular}

Médias seguidas de mesmas letras, maiúscula nas linhas (tratamento), e minúscula nas colunas (cultivar), não diferem entre si ao nível de significância pelo teste não-paramétrico de Friedman e comparações múltiplas $(\mathrm{P}<0,05)$.

\subsection{Matéria seca reprodutiva}

Nas parcelas com controle do inseto (Tabela 11), a formação das vagens seguiu as características de cada cultivar, de acordo com seu ciclo. As eretas, avaliadas até os 99 DAP, tinham nessa época 22,99 a $25,59 \mathrm{~g}$ de vagens por planta. As cultivares rasteiras Runner IAC 886 e Tégua atingiram, aos 112 DAP,
31,80 e 32,31 g planta $^{-1}$ respectivamente. Em 'IACCaiapó', de ciclo mais longo, o enchimento de vagens foi mais lento, com 27,67 g aos 125 DAP. Nas parcelas não tratadas, observou-se a mesma tendência detectada nas parcelas tratadas para todas as cultivares, ou seja, os valores mais altos foram verificados aos 99 DAP para as de porte ereto, e aos 99 e 112 DAP para as rasteiras. 
Tabela 11. Peso da matéria seca reprodutiva (g) em seis épocas de avaliação, durante o ciclo das plantas, em seis cultivares de amendoim, sob infestação natural de Enneothrips flavens em campo. Campinas, SP, $2001 / 2002$.

\begin{tabular}{|c|c|c|c|c|c|c|c|c|}
\hline \multirow{2}{*}{ Tratamento inseticida } & \multirow{2}{*}{ Cultivar } & \multirow{2}{*}{ Porte } & \multicolumn{6}{|c|}{ Dias após o plantio $\left({ }^{1}\right)$} \\
\hline & & & 29 & 56 & 85 & 99 & 112 & 125 \\
\hline \multirow[t]{6}{*}{ Tratado } & IAC-Tatu-ST & Ereto & $0,00 \mathrm{~b}$ & $0,17 \mathrm{~b}$ & $14,84 \mathrm{ab}$ & $23,55 \mathrm{a}$ & - & - \\
\hline & IAC 5 & & $0,00 \mathrm{~b}$ & $0,11 \mathrm{~b}$ & $19,56 \mathrm{ab}$ & $22,99 \mathrm{a}$ & - & - \\
\hline & IAC 22 & & $0,00 \mathrm{~b}$ & $0,00 \mathrm{~b}$ & $16,42 \mathrm{ab}$ & $25,59 \mathrm{a}$ & - & - \\
\hline & Runner IAC 886 & Rasteiro & $0,00 \mathrm{~b}$ & $0,00 \mathrm{~b}$ & $14,64 \mathrm{ab}$ & $27,55 \mathrm{ab}$ & $31,80 \mathrm{a}$ & - \\
\hline & Tégua & & $0,00 \mathrm{~b}$ & $0,00 \mathrm{~b}$ & $13,09 \mathrm{ab}$ & $28,98 \mathrm{a}$ & 32,31 a & - \\
\hline & IAC-Caiapó & & $0,00 \mathrm{~b}$ & $0,00 \mathrm{~b}$ & $9,86 \mathrm{ab}$ & $25,10 \mathrm{ab}$ & $26,27 \mathrm{a}$ & $27,67 \mathrm{a}$ \\
\hline \multirow{6}{*}{$\begin{array}{l}\text { Não } \\
\text { tratado }\end{array}$} & IAC-Tatu-ST & Ereto & $0,00 \mathrm{~b}$ & $0,01 \mathrm{~b}$ & $13,13 \mathrm{ab}$ & $20,26 \mathrm{a}$ & - & - \\
\hline & IAC 5 & & $0,00 \mathrm{~b}$ & $0,08 \mathrm{ab}$ & $14,21 \mathrm{ab}$ & $21,00 \mathrm{a}$ & - & - \\
\hline & IAC 22 & & $0,00 \mathrm{~b}$ & $0,11 \mathrm{ab}$ & $15,88 \mathrm{ab}$ & $18,70 \mathrm{a}$ & - & - \\
\hline & Runner IAC 886 & Rasteiro & $0,00 \mathrm{~b}$ & $0,00 \mathrm{~b}$ & $21,43 \mathrm{ab}$ & $23,97 \mathrm{ab}$ & $27,92 \mathrm{a}$ & - \\
\hline & Tégua & & $0,00 \mathrm{~b}$ & $0,00 \mathrm{~b}$ & $12,01 \mathrm{ab}$ & 20,38 a & $19,44 \mathrm{a}$ & - \\
\hline & IAC-Caiapó & & $0,00 \mathrm{~b}$ & $0,00 \mathrm{~b}$ & 7,99 ab & $22,04 \mathrm{a}$ & $25,62 \mathrm{a}$ & $25,43 \mathrm{a}$ \\
\hline
\end{tabular}

( $\left.{ }^{1}\right)$ Médias comparadas entre épocas de avaliação seguidas de mesma letra nas linhas, dentro de cada cultivar, não diferem entre si ao nível de significância pelo teste não-paramétrico de Friedman e comparações múltiplas $(\mathrm{P}<0,05)$.

Tabela 12. Peso da matéria seca reprodutiva $(\mathrm{g})$ de seis cultivares de amendoim, nas parcelas tratadas e não tratadas com inseticida, em seis épocas durante o ciclo, em condições de infestação natural de Enneothrips flavens em campo. Campinas (SP), 2001/2002

\begin{tabular}{|c|c|c|c|c|}
\hline \multirow{2}{*}{ Dias após o plantio } & \multirow{2}{*}{ Cultivar } & \multirow{2}{*}{ Porte } & \multicolumn{2}{|c|}{ Matéria seca reprodutiva $\left({ }^{1}\right)$} \\
\hline & & & tratado & não tratado \\
\hline & & & & - \\
\hline \multirow[t]{6}{*}{29} & IAC-Tatu-ST & Ereto & 0,00 a $\mathrm{A}$ & 0,00 a $\mathrm{A}$ \\
\hline & IAC 5 & & 0,00 a $\mathrm{A}$ & 0,00 a $\mathrm{A}$ \\
\hline & IAC 22 & & 0,00 a $A$ & 0,00 a $\mathrm{A}$ \\
\hline & Runner IAC 886 & Rasteiro & 0,00 a $\mathrm{A}$ & 0,00 a $\mathrm{A}$ \\
\hline & Tégua & & 0,00 a $\mathrm{A}$ & 0,00 a $\mathrm{A}$ \\
\hline & IAC-Caiapó & & 0,00 a $\mathrm{A}$ & 0,00 a $\mathrm{A}$ \\
\hline \multirow[t]{6}{*}{56} & IAC-Tatu-ST & Ereto & 0,17 a $\mathrm{A}$ & 0,01 a $\mathrm{A}$ \\
\hline & IAC 5 & & 0,11 a $A$ & 0,08 a $\mathrm{A}$ \\
\hline & IAC 22 & & 0,00 a $\mathrm{A}$ & 0,11 a $\mathrm{A}$ \\
\hline & Runner IAC 886 & Rasteiro & 0,00 a $\mathrm{A}$ & 0,00 a $\mathrm{A}$ \\
\hline & Tégua & & 0,00 a $\mathrm{A}$ & 0,00 a $\mathrm{A}$ \\
\hline & IAC-Caiapó & & 0,00 a $\mathrm{A}$ & 0,00 a $\mathrm{A}$ \\
\hline \multirow[t]{5}{*}{85} & IAC-Tatu-ST & Ereto & 14,84 a $\mathrm{A}$ & 13,13 a $\mathrm{A}$ \\
\hline & IAC 5 & & 19,56 a $\mathrm{A}$ & 14,21 a $\mathrm{A}$ \\
\hline & Runner IAC 886 & Rasteiro & 14,64 a $\mathrm{A}$ & 13,43 a $\mathrm{A}$ \\
\hline & Tégua & & 13,09 a $\mathrm{A}$ & 12,01 a $\mathrm{A}$ \\
\hline & IAC-Caiapó & & 9,86 a $\mathrm{A}$ & 7,99 а A \\
\hline \multirow[t]{6}{*}{99} & IAC-Tatu-ST & Ereto & 23,55 a $\mathrm{A}$ & 20,26 a A \\
\hline & IAC 5 & & 22,99 a $\mathrm{A}$ & 21,00 a $\mathrm{A}$ \\
\hline & IAC 22 & & 25,59 a $A$ & 18,70 a $\mathrm{A}$ \\
\hline & Runner IAC 886 & Rasteiro & 27,55 a $\mathrm{A}$ & 23,97 a A \\
\hline & Tégua & & 28,98 a $\mathrm{A}$ & 20,38 a A \\
\hline & IAC-Caiapó & & 25,10 a $\mathrm{A}$ & 22,04 a A \\
\hline \multirow[t]{3}{*}{112} & Runner IAC 886 & Rasteiro & 31,80 a $\mathrm{A}$ & 27,92 a $A$ \\
\hline & Tégua & & 32,31 a $\mathrm{A}$ & 22,44 a $\mathrm{A}$ \\
\hline & IAC-Caiapó & & 26,27 a $A$ & 25,62 a $A$ \\
\hline 125 & IAC-Caiapó & Rasteiro & $27,67 \mathrm{~A}$ & $25,43 \mathrm{~A}$ \\
\hline
\end{tabular}

$\left({ }^{1}\right)$ Médias seguidas de mesmas letras, maiúscula nas linhas (tratamento), e minúscula nas colunas (cultivar), não diferem entre si ao nível de significância pelo teste não-paramétrico de Friedman e comparações múltiplas $(\mathrm{P}<0,05)$. 
Não se detectaram diferenças entre cultivares dentro de cada época de amostragem, dentro das parcelas tratadas e não tratadas (Tabela 12). Embora não significativos, os valores numéricos da massa seca reprodutiva foram menores nas parcelas onde $o$ tripes não foi controlado. Entretanto, as diferenças entre as parcelas tratadas e não tratadas foram proporcionalmente menores do que as obtidas para a massa seca vegetativa, ou seja, os efeitos da praga na parte aérea, observados durante as fases intermediárias de desenvolvimento das plantas, não indicam precisamente a magnitude dos efeitos sobre a parte reprodutiva.

\section{CONCLUSÕES}

1. Independentemente da cultivar, plantas de amendoim são mais infestadas por E. flavens ao redor de 56-57 dias após o plantio (DAP), podendo haver altas infestações nos estádios iniciais de desenvolvimento das plantas em função do ambiente.

2. Dependendo da cultivar plantada, a falta de controle de E. flavens proporciona redução na emissão de brotos e no desenvolvimento vegetativo das plantas.

\section{AGRADECIMENTOS}

À Dr. ${ }^{a}$ Renata Chiarini Monteiro pela identificação da espécie de tripes.

\section{REFERÊNCIAS}

ALMEIDA, P.R.; ARRUDA, H.V. Controle de tripes causador do prateamento das folhas do amendoim por meio de inseticidas. Bragantia, Campinas, v.21, n. 38, p. 679-687, 1962.

AYRES, M.; AYRES JR, M.; AYRES, D.L.; SANTOS, A.S.dos. BioEstat 3.0: aplicação estatísticas nas áreas das ciências biológicas e médicas. Belém: Sociedade Civil Mamirauá; Brasília: CNPq, 2003. 290p.

BOIÇA JUNIOR., A.L.; SANTOS, T.M.; CENTURION, M.A.P.C.; JORGE, J.M. Resistência de genótipos de amendoim Arachis hypogaea L. a Enneothrips flavens Moulton, 1941 (Thysanoptera: Thripidae). Bioscience Journal, Uberlândia, v.20, n.1, p.75-80, 2004.

CALCAGNOLO, G.; LEITE, F.M.; GALLO, J.R. Efeitos da infestação do tripes nos folíolos do amendoinzeiro Enneothrips (Enneothripiella) flavens Moulton, 1941, no desenvolvimento das plantas, na qualidade da produção de uma cultura "da seca". O Biológico, São Paulo, v.40, n.8, p. 239-240, 1974a.
CALCAGNOLO, G.; LEITE, F.M.; GALLO, J.R. Efeitos da infestação do tripes nos folíolos do amendoinzeiro Enneothrips (Enneothripiella) flavens Moulton, 1941, no desenvolvimento das plantas, na qualidade da produção de uma cultura "das águas". O Biológico, São Paulo, v.40, n.8, p. 241-242, 1974 b.

CASTRO, P.R.C.; PITELLI, R.A.; PASSILONGO, R.L. Variações na ocorrência de algumas pragas do amendoinzeiro relacionadas com o desenvolvimento da cultura. Anais da Sociedade Entomológica do Brasil, Itabuna, v.1, n.1, p. 515, 1972.

CONAB- COMPANHIA NACIONAL DE ABASTECIMENTO. Disponível em: http://www.conab.gov.br/conabweb/ index.php?PAG=131. Acesso em 9/10/2006.

GABRIEL, D.; NOVO, J.P.S.; GODOY, I.J.; BARBOZA, J.P. Flutuação populacional de Enneothrips flavens Moulton em cultivares de amendoim. Bragantia, Campinas, v. 55, n. 2, p. 253-257, 1996.

GABRIEL, D.; NOVO, J.P.S.; GODOY, I.J. Efeito do controle químico na população de Enneothrips flavens Moulton e na produtividade de cultivares de amendoim Arachis hipogaea L. O Biológico,São Paulo v. 65, n. 2, p. 51-56, 1998.

GALLO, D.; NAKANO, O.; SILVEIRA NETO, S.; CARVALHO, R.P.L.; BATISTA, G.C.; BERTI FILHO, E.; PARRA, J.R.P.; ZUCCHI, R.A.; ALVES, S.B.; VENDRAMIN, J.D.; MARCHINI, L.C.; LOPES, J.R.S.; OMOTO, C. Entomologia Agrícola. Piracicaba: FEALQ, 920p, 2002.

GODOY, I.J.; MORAES, S.A.; ZANOTTO, M.; SANTOS, R.C. Melhoramento do Amendoim. In: A. Borém (ed.) Melhoramento de Espécies Cultivadas. 1 ed., Viçosa: Universidade Federal de Viçosa, 1999. v.1, p.51-94.

GODOY, I.J.; MORAES, S.A.; ZULLO, M.A., TURATTI, J.M.; PEREIRA, J.C.V.N.A.; MARTINS, A.L.M.; PAULO, E.M. Cultivar de Amendoim IAC-Caiapó: Menor custo de produção, melhor qualidade. Instituto Agronômico: Campinas, 2001a. 6 p. (Fôlder)

GODOY, I.J., MORAES, S.A., MORAES, A.R.A.; KASAI, F.K., MARTINS. A.L.M.; PEREIRA, J.C.V.N.A. Potencial produtivo de linhagens de amendoim do grupo ereto precoce (subespécie fastigiata) com e sem controle de doenças foliares. Bragantia, Campinas, v.60, n.2, p. 101-110, 2001 b.

IAC - INSTITUTO AGRONÔMICO. Cultivar de amendoim IAC-Tatu-ST. Campinas: Instituto Agronômico, 4p. (Folder), 2000a.

IAC - INSTITUTO AGRONÔMICO. Amendoim: Novos Cultivares (em fase Experimental). Campinas: Instituto Agronômico, 2000b. 4p. (Folder)

LASCA, D.H.C.; GODOY, I.J.; MARIOTTO, P.R.; MORAES, S.A.; JOCYS, T.; ROSTON, A.J.; PRATES, H.S.; PELEGRINETTI, J.R. Controle de pragas e doenças da cultura do amendoim. Campinas: CATI, 1983. 10 p. (Boletim Técnico, 174)

MONTEIRO, R.C.; MOUND, L.A.; ZUCCHI, R.A. Thrips (Thysanoptera) as pests of plant production in Brazil. Revista Brasileira de Entomologia, São Paulo, v.43, n. 3/4, p.163-177, 1999. 
MORAES, A.R.A.; LOURENÇÃO, A.L.; GODOY, I.J.; TEIXEIRA, G.C. Infestation by Enneothrips flavens Moulton and yield of peanut cultivars. Scientia Agricola, Piracicaba, v.62, n.5, p. 469-472, 2005.

MORAES, S.A.; GODOY, I.J. Amendoim - Controle de Doenças. In: ZAMBOLIM, L. e VALE, F.X.R. (Eds.). Controle de doenças de plantas: grandes culturas. Viçosa: Universidade Federal de Viçosa; Brasília: Ministério da Agricultura e do Abastecimento, 1997. v.1, n.1, p.1-49.

NAKANO, O.; SILVEIRA NETO, S.; ZUCCHI, R.A. Entomologia Econômica. São Paulo: Agronômica Ceres, 1981. 314 p.
RAIJ, B.; CANTARELLA, H.; QUAGGIO, J.A.; FURLANI, A.M.C. Recomendações de adubação e calagem para o Estado de São Paulo. Campinas: Instituto Agronômico/ Fundação IAC, 1997. 285p. (Boletim Técnico, 100)

SCARPELLINI, J.R.; NAKAMURA, G. Controle do tripes Enneothrips flavens (Moulton, 1941) (Thysanoptera: Thripidae) e efeito na produtividade do amendoim. Arquivos do Instituto Biológico, São Paulo, v.69, n.3, p.85-88, 2002.

STALKER, H.T.; CAMPBELL, W.V. Resistance of wild species of peanut to an insect complex. Peanut Science, Yoakumv. 10, n.1, p. 30-33, 1983. 